\title{
Evaluation of cardiac muscle microvessel density in children diagnosed with cyanotic heart defects
}

\author{
Paulina Jankowska $^{1}$, Agnieszka Malinska ${ }^{2}$, Michal Nowicki², Aneta Konwerska², \\ Michal Wojtalik ${ }^{3}$, Waldemar Bobkowski ${ }^{1}$, Aldona Siwinska ${ }^{1}$
}

${ }^{1}$ Departments of Pediatric Cardiology and Nephrology, University of Medical Sciences in Poznan, Poland

${ }^{2}$ Departments of Histology and Embryology, University of Medical Sciences in Poznan, Poland

${ }^{3}$ Departments of Pediatric Cardiac Surgery, University of Medical Sciences in Poznan, Poland

\begin{abstract}
Angiogenesis is largely an adaptive response to tissue hypoxia, which occurs in a wide variety of situations. Interestingly, the extent of hypoxia-induces angiogenesis in the cardiac muscle of children diagnosed with congenital cyanotic heart defects is not well established. Thus, the aim of this study was to 1) estimate the cardiac muscle microvessel density (MVD) in children diagnosed with cyanotic (study group) and non-cyanotic (control group) heart defects and to 2) evaluate the prognostic significance of MVD value in the development of ventricular dysfunction in the postoperative period. The study group included 42 children diagnosed with cyanotic heart defects. The control group comprised 33 patients with a diagnosis of non-cyanotic heart failure. The collected tissue included cardiac muscle sections from the right atrium and interventricular or interatrial wall during surgical correction of the defect. Immunocytochemistry with monoclonal mouse anti-human antibodies against CD31, CD34 and CD105 was employed to estimate the MVD value. The mean cardiac muscle MVD, defined by CD34 expression, was $596.7 \pm 32.6$ microvessels per $1 \mathrm{~mm}^{2}$ in the study group, which was not significantly different from the mean MVD in the control group (461.2 \pm 30.5$)$. Interestingly, in non-cyanotic heart defects, an inner area of subendocardial meshwork was estimated to have $75.3 \pm 7.0$ microvessels per $1 \mathrm{~mm}^{2}$, compared to $92.8 \pm 10.9$ microvessels per $1 \mathrm{~mm}^{2}(\mathrm{p}=0.0082)$ in patients with cyanotic heart defects. No significant correlations between MVD value and ventricular dysfunction were found. Cyanotic heart defects resulting in chronic hypoxia might provoke angiogenesis in the subendocardial meshwork of the heart wall. The process seems to be independent of the type of cyanotic heart disease and most likely takes place during antenatal development. A ventricular dysfunction observed in some cases of cyanotic heart defects could not be predicted by the estimation of MVD. (Folia Histochemica et Cytobiologica 2013, Vol. 51, No. 4, 278-285)
\end{abstract}

Key words: microvessel density; cyanotic heart defect; prognosis; heart biopsy; CD34; CD105; angiogenesis

\section{Introduction}

Anatomic abnormalities in cyanotic congenital heart defects result in decreased pulmonary blood flow and lead to systemic hypoxia [1]. Moreover, patients with these types of defects frequently develop ventricular dysfunction in the postoperative period [2]. However,

Correspondence address: $M$. Nowicki, Department of Histology and Embryology, University of Medical Sciences in Poznan, Swiecickiego St. 6, 60-781 Poznan, Poland; tel:. +48 6185464 53; fax: +48 6185464 40;

e-mail:mnowicki@ump.edu.pl the histological basis of these functional alterations is not clear. Individual investigations have reported significant differences in cardiomyocyte diameter, amount of collagen fibers and microvessel density (MVD) in different regions of the myocardium in patients with Fallot's tetralogy [2].

Chronic hypoxia provokes the systemic modification of internal organ structure and function [1]. Angiogenesis is largely an adaptive response to tissue hypoxia, which occurs in a wide variety of situations [3, 4]. Interestingly, the extent of hypoxia-induces angiogenesis in the cardiac muscle of children diagnosed with congenital cyanotic heart defects is not yet well established $[2,5]$. 
One of the most sensitive histological parameters that reflects the extent of anoxia involves MVD, which can be defined by the relative expression levels of CD31, CD34 and/or CD105 [6]. CD31 is expressed on the surface of the continuous endothelium of mature blood vessels. It is a $130 \mathrm{kDa}$ transmembrane protein with an important role as an adhesion molecule for endothelial-endothelial cell interactions and leukocyte -endothelial cell interactions [7, 8]. CD34 is expressed on the surface of most bone marrow hematopoietic cells and mature endothelial cells. Interestingly, it is highly expressed during the preliminary stages of endothelial progenitor cell development and in later stages of blood vessel development [7]. Therefore, the estimation of CD34 expression allows for the evaluation of mature and developing blood vessels. Quantification of the combined CD31 and CD34 expression or the calculation of the $\mathrm{CD} 34 / \mathrm{CD} 31$ ratio provides a determination of the fraction and location of blood vessels with a relatively higher angiogenic potential. These parameters allow for an indirect estimation of relative tissue anoxia during morphogenesis and angiogenesis [9]. Additionally, the ratio of CD105 (endoglin) to CD31 is widely used as an indicator of angiogenesis [10]. CD105 is a proliferation-associated and hypoxia-inducible factor abundantly expressed in activated endothelial cells and is a receptor for transforming growth factor $[11,12]$.

In line with the above, the aim of the present research was to 1) estimate cardiac muscle microvessel density in children diagnosed with cyanotic (study group) and non-cyanotic (control group) heart defects by means of immunohistochemistry and morphometry and to 2) evaluate the prognostic significance of MVD value in the evolution of ventricular dysfunction in the postoperative period.

\section{Material and methods}

Patients. The study group included 42 children diagnosed with cyanotic heart defects ( 23 boys and 19 girls; mean age $3.4 \pm 2.1$ years). The control group comprised 33 patients diagnosed with a non-cyanotic heart defect (19 boys and 14 girls; mean age $8.2 \pm 3.7$ years).

The cyanotic heart defects included tetralogy of Fallot $(\mathrm{n}=8)$, Ebstein's anomaly $(\mathrm{n}=2)$, atresia of the pulmonary valve $(n=9)$, tricuspid atresia $(n=13)$ and transposition of the great vessels $(n=10)$. The non-cyanotic heart defects included ventricular septal defect $(\mathrm{n}=9)$, atrial septal defect $(\mathrm{n}=14)$, patent ductus arteriosus $(\mathrm{n}=8)$ and coarctation of the aorta $(n=2)$.

All of the patients were surgically treated in the Department of Pediatric Cardiac Surgery, University of Medical Sciences in Poznan, Poland between March 15 ${ }^{\text {th }}, 2010$ and September $15^{\text {th }}, 2011$. The research protocol was approved by the Ethics Committee of Poznan University of Medical Sciences, and the parents of all participants gave informed consent for the investigation. All of the analyses were performed blind on coded samples. The patients' preoperative data are summarized in Table 1.

Surgical procedure. The tissue examined originated from the cardiac interventricular or interatrial septum or from the atrial wall and was removed during the surgical correction of heart defects. Detailed information about the tissue origin in each group is presented in Table 1. One day before cardiac surgery, complete blood morphology was estimated for each patient, including C-reactive protein value and coagulation parameters. Following the anesthetization of the patient and opening of the thorax in a stereotypical manner, sutures were applied to the aorta and right atrium to couple the patient to extracorporeal circulation. Aortal cannula was introduced, and the opening was broadened to insert a cannula into the vena cava superior. A fragment of the right atrium wall was taken for the studies. During the heart defect correction surgery, two or three fragments of interatrial or interventricular septum were taken for the studies. The excision of these fragments was medically necessary to apply the correcting patch and to fit it to cardiac structures [13].

The excised samples were fixed in Bouin's solution at room temperature for $24 \mathrm{~h}$ and embedded in paraffin.

Immunohistochemistry. Briefly, deparaffinized 3-4 $\mu \mathrm{m}$ sections were pre-treated in a microwave $(800 \mathrm{~W}$, citrate buffer). To analyze CD31, CD34 and CD105 expression in cardiac biopsies, an indirect immunocytochemical procedure (the streptavidin-biotin complex method with the use of horseradish peroxidase) was performed using monoclonal mouse anti-human antibodies against CD31 (Dako, Copenhagen, Denmark; M00823, diluted 1:100), CD34 (Dako, M7165, diluted 1:100) and CD105 (Dako, M3257, diluted 1:150). Following incubation with the primary antibody for $24 \mathrm{~h}$ at $4^{\circ} \mathrm{C}$, the specimens were treated for $1 \mathrm{~h}$ at room temperature with biotin-conjugated goat anti-mouse $\mathrm{IgG}$ (Sigma, Munich, Germany; diluted 1:300). Subsequently, the sections were incubated with an $\mathrm{ABC}$ reagent (Vectastain, Elite; Vector, Burlingame, CA, USA) for $45 \mathrm{~min}$ at room temperature. The activity of peroxidase was detected by treating the sections with $0.5 \%$ 3,3'-diaminobenzidine in Tris/ $/ \mathrm{HCl}(\mathrm{pH}=7.6)$ containing $0.3 \% \mathrm{H}_{2} \mathrm{O}_{2}$. Finally, the sections were counterstained with hematoxylin. Normal mouse IgG at the same concentrations as the primary antibodies (Dako, $\mathrm{X}$ 0931, diluted 1:100) or phosphate buffer saline (PBS) were used as negative controls.

Morphometric and statistical analyses. A sequence of 5 serial preparations was quantified in all of the patients for expression of CD31, CD34 and CD105. Images were acquired using a high-resolution scanning technique (working magnification of $400 \times$ with the autofocus function) 
Table 1. Patients' data (preoperative)

\begin{tabular}{|c|c|c|c|}
\hline & Cyanotic heart defect $(n=42)$ & Non-cyanotic heart defect $(n=33)$ & p-value \\
\hline Gender (male/female) & $23 / 19$ & $19 / 14$ & ns \\
\hline Age (years) & $3.4 \pm 2.1$ & $8.2 \pm 3.7$ & $\mathrm{p}<0.01$ \\
\hline Diagnosis & $\begin{array}{l}\text { TOF }(n=8) \\
\text { Ebstein's anomaly }(\mathrm{n}=2) \\
\text { Pulmonary atresia }(\mathrm{n}=9) \\
\text { Tricuspid atresia }(\mathrm{n}=13) \\
\text { TGV }(\mathrm{n}=10)\end{array}$ & $\begin{array}{l}\operatorname{VSD}(n=9) \\
\operatorname{ASD}(n=14) \\
\operatorname{PDA}(n=8) \\
\text { Aortic coarctation }(n=2)\end{array}$ & \\
\hline BMI $\left[\mathrm{kg} / \mathrm{m}^{2}\right]$ & $17.2 \pm 1.8$ & $18.5 \pm 2.2$ & ns \\
\hline $\begin{array}{l}\text { Preoperative } \mathrm{O}_{2} \text { satu- } \\
\text { ration }\end{array}$ & $84.6 \pm 3.3$ & $96.5 \pm 2.8$ & $\mathrm{p}<0.01$ \\
\hline $\begin{array}{l}\text { Tissue origin obtained } \\
\text { during surgery }\end{array}$ & $\begin{array}{l}\text { Interatrial septum }(\mathrm{n}=6) \\
\text { Interventricular septum }(\mathrm{n}=14) \\
\text { Atrial wall }(\mathrm{n}=22)\end{array}$ & $\begin{array}{l}\text { Interatrial septum }(\mathrm{n}=14) \\
\text { Interventricular septum }(\mathrm{n}=9) \\
\text { Atrial wall }(\mathrm{n}=10)\end{array}$ & \\
\hline $\begin{array}{l}\text { Diastolic interatrial wall } \\
\text { thickness }[\mathrm{mm}]\end{array}$ & $\begin{array}{l}\text { TOF }(0.8 \pm 0,2) \\
\text { Ebstein's anomaly }(0.7 \pm 0.2) \\
\text { Pulmonary atresia }(0.7 \pm 0.2) \\
\text { Tricuspid atresia }(0.8 \pm 0.1) \\
\text { TGV }(0.9 \pm 0.3)\end{array}$ & $\begin{array}{l}\text { VSD }(0.8 \pm 0.2) \\
\text { ASD }(0.6 \pm 0.2) \\
\text { PDA }(0.7 \pm 0.1) \\
\text { Aortic coarctation }(0.8 \pm 0.2)\end{array}$ & ns \\
\hline $\begin{array}{l}\text { Diastolic Interventricu- } \\
\text { lar wall thickness [mm] }\end{array}$ & $\begin{array}{l}\text { TOF }(0.9 \pm 0.2) \\
\text { Ebstein's anomaly }(1.0 \pm 0.2) \\
\text { Pulmonary atresia }(1.0 \pm 0.3) \\
\text { Tricuspid atresia }(0.9 \pm 0.3) \\
\operatorname{TGV~}(1.3 \pm 0.3)\end{array}$ & $\begin{array}{l}\text { VSD }(0.9 \pm 0.1) \\
\text { ASD }(0.9 \pm 0.2) \\
\text { PDA }(1.0 \pm 0.2) \\
\text { Aortic coarctation }(1.2 \pm 0.4)\end{array}$ & ns \\
\hline
\end{tabular}

ns — not significant; TOF — tetralogy of Fallot; TGV — transposition of the great vessels; VSD — ventricular septal defect; ASD — atrial septal defect; PDA — patent ductus arteriosus

and the MiraxMidi microscope scanner (Carl Zeiss, Poznan, Poland). The resulting graphic file, encompassing the entire preparation surface, was subjected to morphologic and morphometric analysis using MiraxViewer software (Carl Zeiss).

To determine MVD, three regions of each preparation with the highest number of blood vessels were subjected to analysis ('hot-spots' technique), and the mean blood vessel density (number of blood vessels per $1 \mathrm{~mm}^{2}$ ) was calculated, dividing the average number of blood vessels in 'hot-spots' by the area of the field [14]. This procedure was applied separately for CD31, CD34 and CD105. Finally, the CD34/ /CD31 and CD105/CD31 angiogenic indices were calculated to optimize the activated blood vessel ratio, which could be then used in the evaluation of prognostic significance in children diagnosed with cyanotic heart defects. In the subsequent stage of the studies, MVD values were determined in regions of the sample that are most susceptible to the effects of chronic anoxia (e.g., peripheral portions of the preparation in the vicinity of the atrial and ventricular lumen). Such an analysis, however, was not based on the 'hot-spots' approach, and all blood vessel cross-sections were scored (with expression of CD31, CD34 and CD105).

Continuous or interval-related variables were expressed as the means $\pm \mathrm{SD}$. Comparisons of continuous variables between groups were performed using Student's $t$-test.
Comparisons of discrete variables between groups were performed using the Mann-Whitney test. Alpha adjustment for all of the multiple comparisons used Bonferroni correction. Independent risk factors for ventricular dysfunction and the relationship between age or gender and MVD within each analyzed group were determined using Fisher's exact test. The cut-off points for age were arbitrarily estimated at 18 months and 4 years for cyanotic and non-cyanotic defects, respectively. For MVD, an arbitrary cut-off point was set at 400 microvessels per $1 \mathrm{~mm}^{2}$ in all of the patient samples. $\mathrm{P}<0.05$ was considered statistically significant.

\section{Results}

\section{Clinical observation}

The post-operative observation protocol varied depending on the type of complications. Twenty-eight children from the study group and 27 patients from the control group demonstrated no significant complications and were released within 14 days after the surgery. Six children in the study group and 2 subjects from the control group developed a transient left ventricular dysfunction (characterized by tachyp- 
nea, pulmonary edema and cyanosis) and required a subsequent surgery. The ejection fraction (EF) of patients suffering from this complication, estimated by echocardiography, was $>30 \%$. Four children in the study group and two patients in the control group developed pneumonia. EF in these study participants was between 30 and $55 \%$. Sepsis or severe wound infection were diagnosed in two children from the study group and a single child in the control group. These patients required a longer hospital stay. Finally, a single patient with a non-cyanotic heart defect and two children with cyanotic heart disease died in the period between 1 and 7 days after surgery (Table 2).

\section{Evaluation of MVD value in cardiac muscle biopsies}

We compared the MVD between cyanotic and non-cyanotic patients by quantifying CD31, CD34 or CD105 expression. In the study group, the mean MVD (determined by 'hot-spots' technique) assessed by CD31 expression was $405.8 \pm 26.9$ microvessels per $1 \mathrm{~mm}^{2}$. The mean MVD determined by CD34 expression was $596.7 \pm 32.6$ microvessels per $1 \mathrm{~mm}^{2}(\mathrm{p}=0.01)$ in the study group. The number of CD105-positive blood vessels in $1 \mathrm{~mm}^{2}$ of cardiac muscle biopsies of patients in the study group ranged from 483.6 and 529.2, and an average MVD defined by CD105 expression was $505.3 \pm 25.6$ microvessels per $1 \mathrm{~mm}^{2}(\mathrm{p}=0.03$ compared to CD31 and CD34). Analogously, the control group MVD value, determined by CD31 or CD34 expression, was $315.6 \pm 23.6$ and $461.2 \pm 30.5$ microvessels per $1 \mathrm{~mm}^{2}(\mathrm{p}<0.001)$, respectively, and $388.3 \pm 19.2$ microvessels per $1 \mathrm{~mm}^{2}$ when defined by CD105 expression ( $\mathrm{p}=0.04$ compared to CD31 and CD34).

An average CD34/CD31 index in cardiac muscle biopsies from the study group was 1.47 , and the mean CD105/CD31 ratio was 1.25 (not significant). In the control group, the CD34/CD31 index was 1.46, and the CD105/CD31 ratio was 1.23 (not significant). The mean cardiac microvessel density in cyanotic patients was not statistically significantly different than the mean MVD in non-cyanotic patients (Figure 1).

We next examined a subendocardial area of the cardiac wall (known for its constitutive vessel destitution) for MVD value. We found that the MVD value defined by CD31 expression was $61.9 \pm 13.3$ microvessels per $1 \mathrm{~mm}^{2}$ in the control group, while CD34 and CD105 expressions estimated the MVD to be $75.3 \pm 7.0$ and $72.4 \pm 5.6$, respectively (not significant). In contrast, the CD31 MVD value $71.1 \pm 9.5$ microvessels per $1 \mathrm{~mm}^{2}$ in the control group, while the CD34 and CD105 MVD calculations were significantly higher at $92.8 \pm 10.9$ and $89.9 \pm 7.3$,
Table 2. Patients' data (postoperative)

\begin{tabular}{|l|l|l|l|}
\hline & $\begin{array}{l}\text { Cyanotic } \\
\text { heart } \\
\text { defect } \\
(\mathbf{n}=\mathbf{4 2})\end{array}$ & $\begin{array}{l}\text { Non- } \\
\text {-cyanotic } \\
\text { heart } \\
\text { defect } \\
(\mathbf{n}=\mathbf{3 3})\end{array}$ & p-value \\
\hline $\begin{array}{l}\text { No complications (male// } \\
\text { female) }\end{array}$ & $13 / 15$ & $15 / 12$ & $\mathrm{~ns}$ \\
\hline $\begin{array}{l}\text { Transient left ventricular } \\
\text { dysfunction (male/female) }\end{array}$ & $3 / 3$ & $1 / 1$ & $\mathrm{p}<0.01$ \\
\hline Pneumonia (male/female) & $3 / 1$ & $1 / 1$ & $\mathrm{p}<0.01$ \\
\hline Sepsis (male/female) & $2 / 0$ & $1 / 0$ & $\mathrm{~ns}$ \\
\hline $\begin{array}{l}\text { Death } \\
\text { (male/female) }\end{array}$ & $2 / 0$ & $1 / 0$ & $\mathrm{~ns}$ \\
\hline
\end{tabular}

ns - not significant

respectively ( $\mathrm{p}=0.005$, CD31 vs. CD34 expression; $\mathrm{p}=0.008$, study group $v s$. control group). These findings are illustrated in Table 3 and Figures 2 and 3.

Differences in CD31, CD34 and CD105 expression and MVD values, CD34/CD31 and CD105/CD31 angiogenic ratios did not correlate with age or gender of patients or early treatment failures, as determined by clinical observation. Moreover, there was no significant difference in MVD value within the studied groups when comparing different tissues (atrial wall, interatrial septum or interventricular septum).

\section{Discussion}

The subendocardial meshwork (area) is a small region (restricted to $150-200 \mu \mathrm{m}$ ) in the cardiac wall of the left ventricle, ventricular septum, or papillary muscles, which is the farthest from the heart's blood supply and is more susceptible to systemic hypoxia [15]. Oxygen and nutrients are usually supplied indirectly from the blood stream in the ventricle. Subendocardial infarctions in adults are thought to be a result of locally decreased blood supply, possibly from a narrowing of the coronary arteries $[16,17]$.

In the present study, the mean MVD value in the subendocardial area was significantly larger in patients diagnosed with cyanotic heart defects compared to non-cyanotic study participants. The mean age of patients with cyanotic defects was significantly lower compared to non-cyanotic patients. Furthermore, the non-cyanotic group of children underwent a cardiac surgery at a later age, due to less severe heart disease. Interestingly, the MVD value in the cardiac wall, with the exception of the subendocardial meshwork, was comparable between cyanotic and non-cyanotic heart diseases. These data may indicate systemic hypoxia in cyanotic hearts even during prenatal development, 

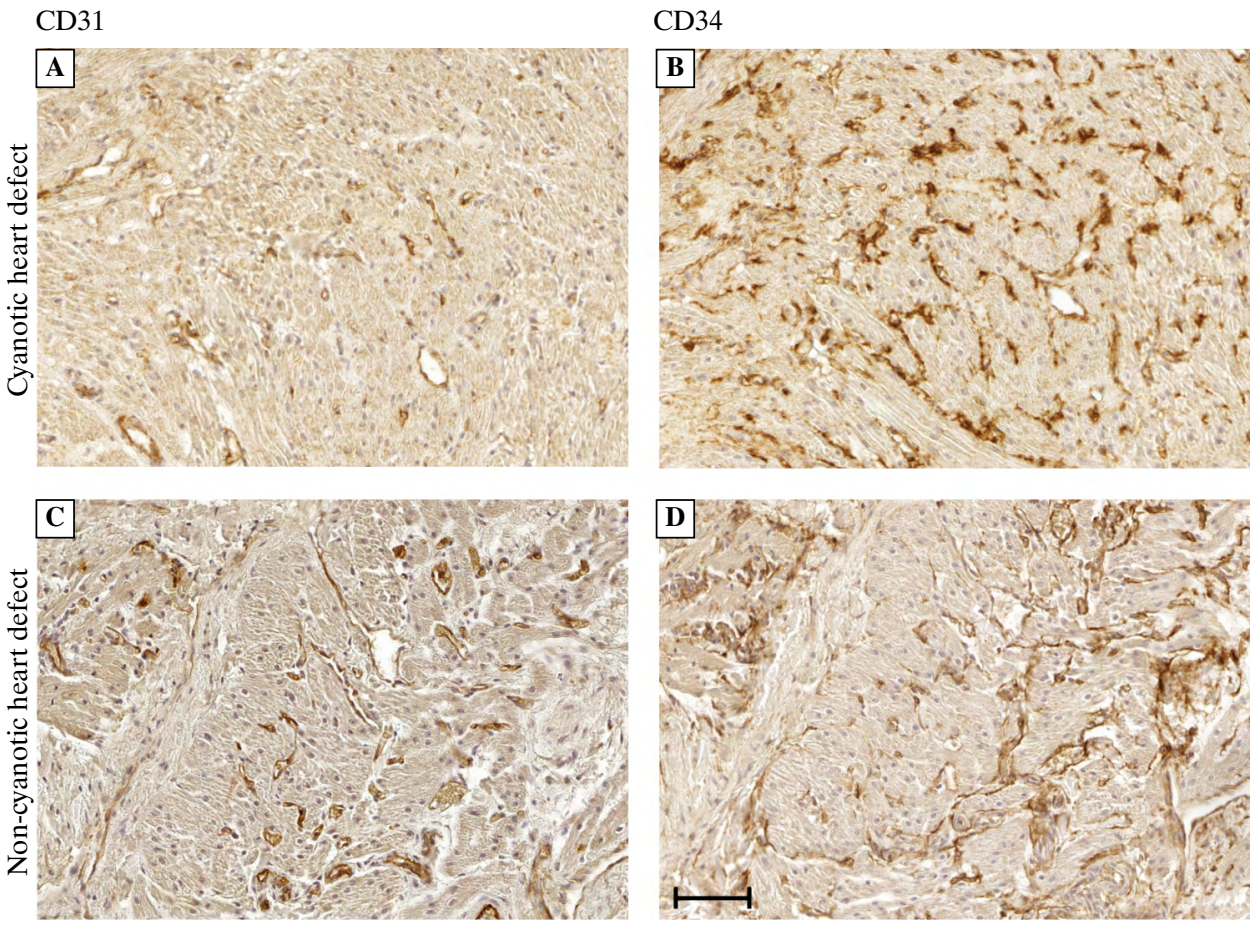

Figure 1. Demonstration of microvessels density in cardiac muscle biopsies of children with congenital heart defects. Sections were stained by immunohistochemistry to show the MVD defined by CD31 (A and C) and CD34 (B and D) expression. A and B were obtained from a representative child diagnosed with cyanotic heart defect (transposition of the great vessels). $\mathbf{C}$ and $\mathbf{D}$ were obtained from a patient with non-cyanotic heart disease (atrial septal defect type II). SM = subendocardial meshwork. CD34 expression seems to be a more valuable marker than CD31 for the estimation of MVD in cardiac biopsies. Scale bar $=150 \mu \mathrm{m}$

Table 3. Morphometric evaluation of vessels in the subendocardial tissue of children with cyanotic and non-cyanotic heart disease

\begin{tabular}{|c|c|c|c|}
\hline & $\begin{array}{l}\text { Cyanotic } \\
\text { heart defect } \\
(\mathbf{n}=\mathbf{4 2})\end{array}$ & $\begin{array}{l}\text { Non-cyanotic } \\
\text { heart defect } \\
(n=33)\end{array}$ & p-value \\
\hline $\begin{array}{l}\text { Microvessel diameter } \\
{[\mu \mathrm{m}]}\end{array}$ & $13 \pm 5.6$ & $12 \pm 4.1$ & ns \\
\hline $\begin{array}{l}\text { MVD CD31 [ves- } \\
\text { sels/ } 1 \mathrm{~mm}^{2} \text { ] }\end{array}$ & $405.8 \pm 26.9$ & $315.6 \pm 23.6$ & ns \\
\hline $\begin{array}{l}\text { MVD CD34 [ves- } \\
\text { sels/1 } \mathrm{mm}^{2} \text { ] }\end{array}$ & $596.7 \pm 32.6^{*}$ & $461.2 \pm 30.5^{\# \#}$ & $\mathrm{p}<0.05$ \\
\hline $\begin{array}{l}\text { MVD CD105 [ves- } \\
\text { sels/1 mm²] }\end{array}$ & $\begin{array}{l}505.3 \pm \\
25.6^{*}\end{array}$ & $388.3 \pm 19.2^{\#}$ & $\mathrm{p}<0.05$ \\
\hline CD34/CD31 & 1.47 & 1.46 & ns \\
\hline CD105/CD31 & 1.25 & 1.23 & ns \\
\hline $\begin{array}{l}\text { Subendocardial MVD } \\
\text { CD31 [vessels/1 mm²] }\end{array}$ & $71.1 \pm 9.5$ & $61.9 \pm 13.3$ & ns \\
\hline $\begin{array}{l}\text { Subendocardial MVD } \\
\text { CD34 [vessels/1 } \mathrm{mm}^{2} \text { ] }\end{array}$ & $92.8 \pm 10.9$ & $75.3 \pm 7.0$ & $\mathrm{p}<0.01$ \\
\hline $\begin{array}{l}\text { Subendocardial MVD } \\
\text { CD105 [vessels } / 1 \mathrm{~mm}^{2} \text { ] }\end{array}$ & $89.9 \pm 7.3$ & $72.4 \pm 5.6$ & $\mathrm{p}=0.008$ \\
\hline
\end{tabular}

MVD CD31,-CD34 and-CD105 - microvessel density defined by the expression of CD31, CD34 and CD105, respectively; *p $<0.01$ compared to 'cyanotic' heart defect; " $\mathrm{p}<0.001$ compared to 'non-cyanotic' heart defect; CD34/CD31, angiogenic ratio defined as MVD CD34 to MVD CD31 ratio; CD105/CD31, angiogenic ratio defined as MVD CD105 to MVD CD31 ratio and an increase in the formation of blood vessels in the area closest to the ventricular or atrial lumen of the heart. In non-cyanotic patients, this part of the cardiac wall was not occupied by an increased number of blood vessels, which might suggest that the age of the patients or the delayed time of surgery do not affect neovascularization. Interestingly, the diastolic thickness of the interatrial or interventricular wall in cyanotic or non-cyanotic children was not significantly different. The mean thickness values were reported in previous studies [18].

It must be emphasized that endothelial progenitor cells (EPCs) contain three types of cells [19], including early endothelial progenitor cells, recruited from stem cells of bone marrow stroma [20], and early and late endothelial progenitor cells, which circulate in the blood [21].

Early and late forms of circulating EPCs are characterized by the gradual decrease in CD133 expression, with an increase in CD105, CD31 and von Willebrand's factor expression [4]. Of note, late EPCs no longer express CD133, while the presence of CD34 is variable [21-23]. CD105 is a much more specific marker than leukocyte antigen CD34 and is a useful marker for activated endothelial cells. CD34 is a common blood vessel marker for both mature and developing endothelial cells [10-12]. In this study, 

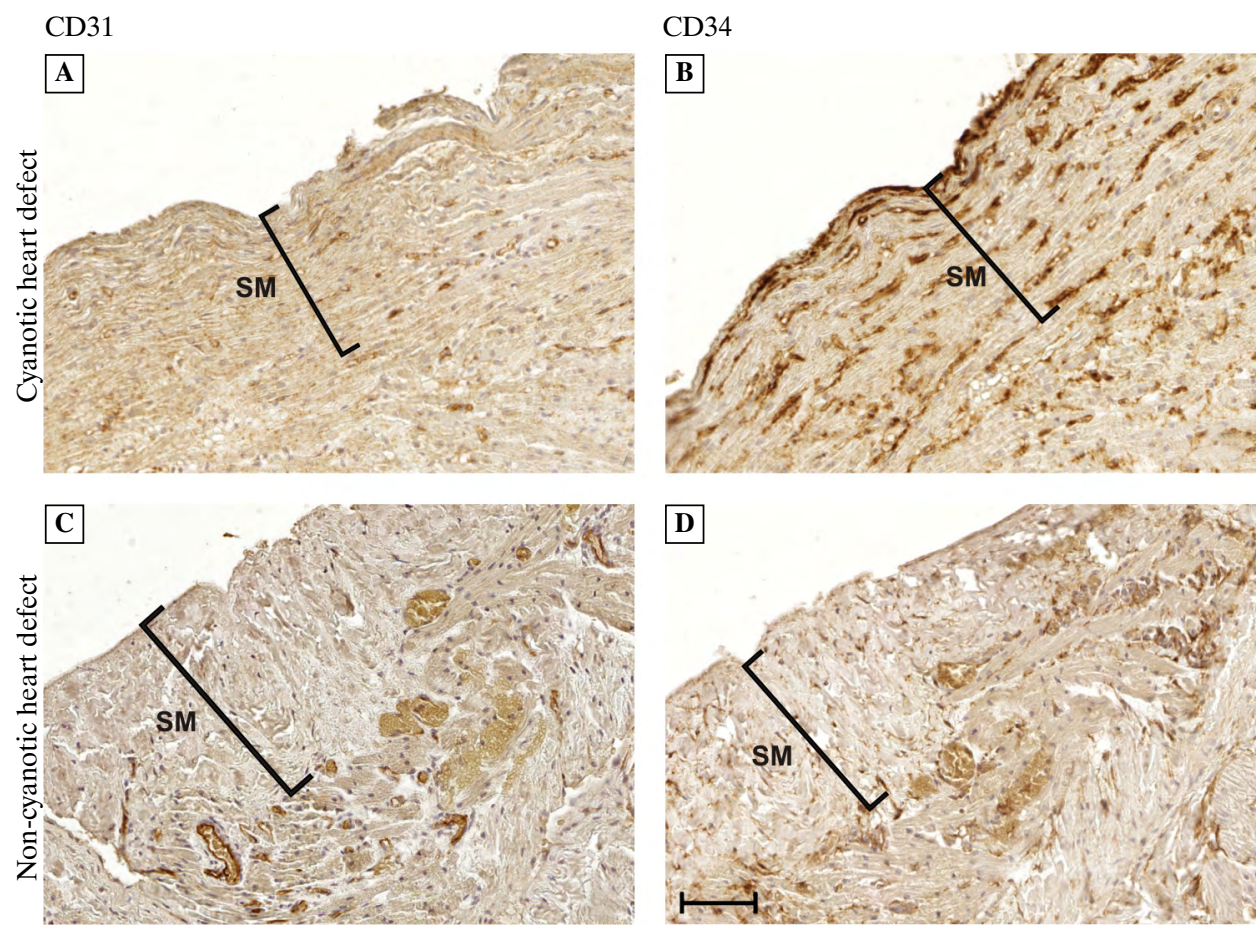

Figure 2. Demonstration of microvessels density in subendocardial meshwork of children with congenital heart defects. Sections show the immunoreactivity of CD31 (A and C) and CD34 (B and D) in microvessels. A and B, transposition of the great vessels; C and D, non-cyanotic heart defects (atrial septal defect type II). A significantly higher number of vessels was present in the subendocardial heart tissue in cyanotic heart diseases. CD34 staining was a more accurate marker for the determination of the MVD value. Scale bar $=150 \mu \mathrm{m} ; \mathrm{SM}=$ subendocardial meshwork

we found that MVD estimations by CD34 or CD105 expression did not significantly differ in cardiac muscle biopsies of the control and study groups. Moreover, the CD34/CD31 index was similar to the CD105/CD31 ratio in both cyanotic and non-cyanotic heart defects. These results indicate that in cardiac muscle biopsies, the number of activated blood vessels (defined by expression of CD105) is similar to the number of all blood vessels (defined by means of CD34). Thus, just two markers, CD31 and CD34, may define the degree of endothelial maturity in a precise way.

The principal observation stemming from this study is linked to significant differences in the expression of CD31 and CD34 within the same sections of myocardium. This might indicate that CD31 does not represent a sufficiently good marker for the estimation of MVD in cyanotic and non-cyanotic heart defects. Alternatively, CD31 and CD34 distributions are distinct. Subendocardial regions of cardiac sections contained a significantly higher number of CD34- and CD105-positive blood vessels in the study group compared to the control group of noncyanotic heart defects. This observation was surprising because CD31 expression alone could not detect the difference in MVD between the two groups of heart defect patients. These discrepancies may be due to the relatively small sample size and lack of prior research studies on the topic.

The MVD values in cardiac muscle of children with congenital heart diseases reported in this study are one of the first results obtained for this group of diseases. Earlier studies focused primarily on myocardial reconstruction during cardiac overload pathology. Rakusan et al. [24] found that the density of capillaries in hypertensive overload of the left cardiac ventricle was directly related to the severity of the defect. In adults, myocardial hypertrophy was found to result from compromised angiogenic compensation.

Cardiac vessel density itself can be estimated by CD31 expression. Angio T cell factor was first used to demonstrate the vasculoprotective abilities and neoangiogenesis of CD31-positive blood vessels [24]. Kushner et al. [25] previously demonstrated that changes in subpopulations of CD31-positive cells decrease angiogenic potential and augment the probability of developing age-related circulatory diseases. Thus, MVD has been recognized as a prognostic factor for the adaptive tissue potential for anoxia [26].

In the case of congenital heart defects, we propose that CD34 expression is a good marker for the evaluation of MVD and may also be used as an index for anoxia in selected regions of myocardial samples. 

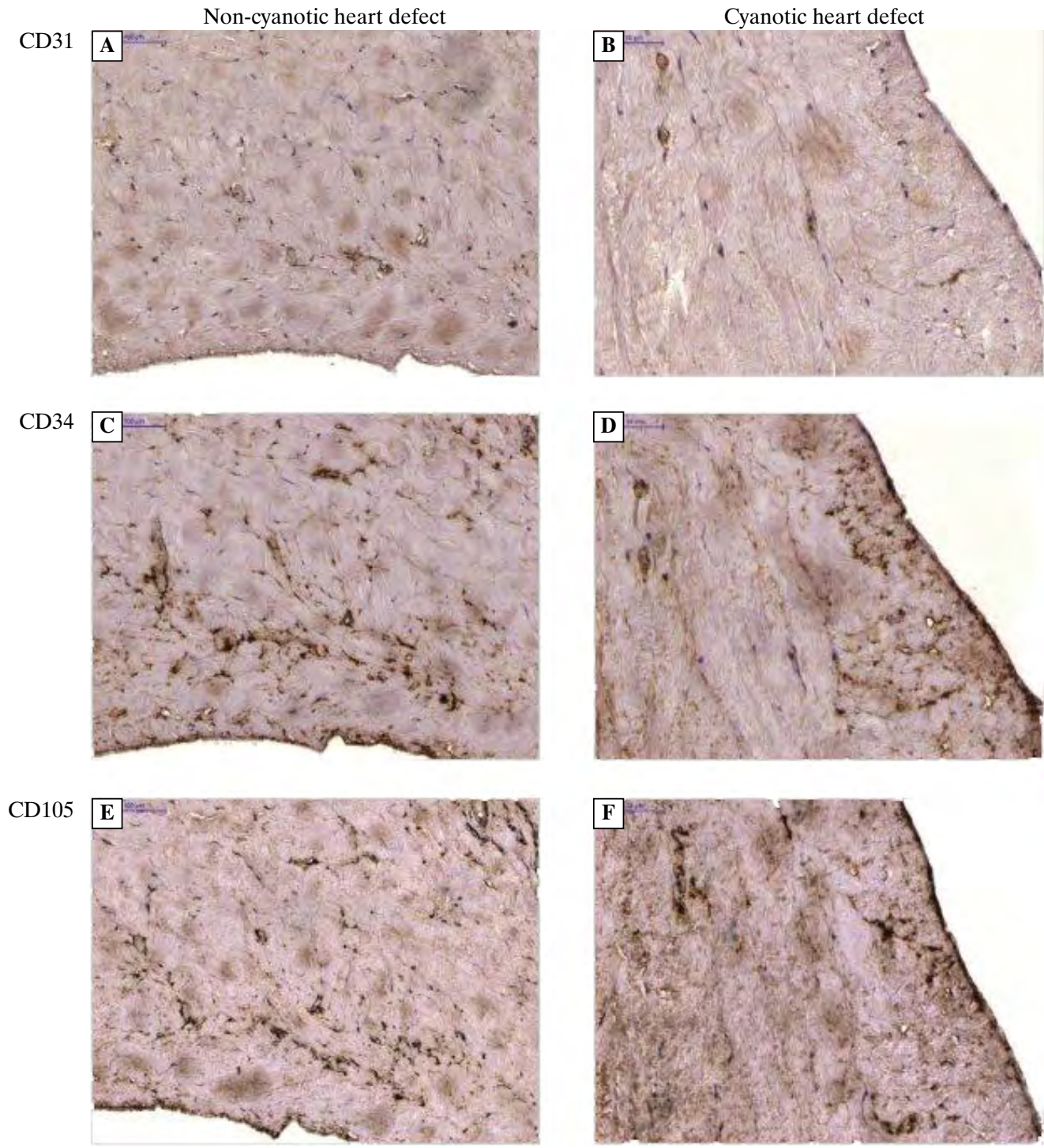

Figure 3. Comparison of CD31, CD34 and CD105 expression on serial cardiac slides in cyanotic and non-cyanotic heart defects. A, C, E - atrial septal defect type II; B, D, F - Fallot's tetralogy. Immunoreactivity of CD31 did not differ between non-cyanotic (A) and cyanotic (B) heart defects. Expression of CD34 was significantly higher compared to CD31, especially in the subendocardial meshwork (D). Immunoreactivity of CD105 was significantly higher compared to CD31 and slightly lower compared to CD34 expression. Scale bar $=150 \mu \mathrm{m}$

The observed post-surgery complications, including sepsis and pneumonia, need a separate attention. According to previous observations made by us and other research groups, all the other differences in both study groups were secondary to differences in age and immune system immaturity and incompetence.

In conclusion, cyanotic heart defects resulting in chronic hypoxia might exclusively provoke angiogenesis in the subendocardial meshwork of the heart wall. The angiogenic process is independent of the type of cyanotic heart disease and most likely takes place during antenatal development. A ventricular dysfunction observed in some cases of cyanotic heart defects could not be predicted by the estimation of MVD.

\section{Acknowledgements}

The authors wish to thank Professor Elzbieta Kaczmarek for her contribution in statistical analysis. This publication was also a part of NCN project NN 401 601738

\section{References}

1. Cordina RL, Celermajer DS. Chronic cyanosis and vascular function: implications for patients with cyanotic congenital heart disease. Cardiol Young. 2010;20:242-253.

2. Farah MC, Castro CR, Moreira VM et al. The myocardium in tetralogy of Fallot: a histological and morphometric study. Arq Bras Cardiol. 2009;92:160-171.

3. Berger S, Lavie L. Endothelial progenitor cells in cardiovascular disease and hypoxia - potential implications to 
obstructive sleep apnea. Transl Res. 2011;158:1-13.

4. Nowicki M, Konwerska A, Ostalska-Nowicka D et al. Vascular endothelial growth factor (VEGF)-C - a potent risk factor in children diagnosed with stadium 4 neuroblastoma. Folia Histochem Cytobiol. 2008;46:493-499.

5. Padalino MA, Castellani C, Toffoli S et al. Pathological changes and myocardial remodelling related to the mode of shunting following surgical palliation for hypoplastic left heart syndrome. Cardiol Young. 2008;18:415-422.

6. Raica M, Cimpean AM, Ribatti D. Angiogenesis in pre-malignant conditions. Eur J Cancer. 2009;45:1924-1934.

7. Mödder UI, Roforth MM, Nicks KM et al. Characterization of mesenchymal progenitor cells isolated from human bone marrow by negative selection. Bone. 2012;50:804-810.

8. Nico B, Benagiano V, Mangieri D et al. Evaluation of microvascular density in tumors: pro and contra. Histol Histopathol. 2008;23:601-607.

9. De Raeve H, Van Marck E, Van Camp B et al. Angiogenesis and the role of bone marrow endothelial cells in haematological malignancies. Histol Histopathol. 2004;19:935-950.

10. Tachezy M, Reichelt U, Melenberg T et al. Angiogenesis index CD105 (endoglin)/CD31 (PECAM-1) as a predictive factor for invasion and proliferation in intraductal papillary mucinous neoplasm (IPMN) of the pancreas. Histol Histopathol. 2010;25:1239-1246.

11. Fonsatti E, Del Vecchio L, Altomonte $\mathrm{M}$ et al. Endoglin: An accessory component of the TGF-beta-binding receptor-complex with diagnostic, prognostic, and bioimmunotherapeutic potential in human malignancies. J Cell Physiol. 2001;188:1-7.

12. Pierelli L, Bonanno G, Rutella S et al. CD105 (endoglin) expression on hematopoietic stem/progenitor cells. Leuk Lymphoma. 2001;42:1195-1206.

13. Pawelec-Wojtalik M, Mroziński B, Westerski P et al. Closure of major aorto-pulmonary collateral artery with the Amplatzer vascular plug in an infant with pulmonary atresia and ventricular septal defect - a difficult therapeutic problem. Kardiol Pol. 2009;67:420-423.

14. Kvasnicka HM, Thiele J. Bone marrow angiogenesis: methods of quantification and changes evolving in chronic myeloproliferative disorders. Histol Histopathol. 2004;19:1245-1260.
15. Engberding R, Yelbuz TM, Breithardt G. Isolated noncompaction of the left ventricular myocardium - a review of the literature two decades after the initial case description. Clin Res Cardiol. 2007;96:481-488.

16. Kothawade K, Bairey Merz CN. Microvascular coronary dysfunction in women: pathophysiology, diagnosis, and management. Curr Probl Cardiol. 2011;36:291-318.

17. Burke AP, Virmani R. Pathophysiology of acute myocardial infarction. Med Clin North Am. 2007;91:553-572.

18. Huang JB, Liang J, Du M. Clinical and pathologic comparison of simple left-to-right shunt congenital heart disease and transposition of the great arteries with ventricular septal defect. Heart Surg Forum. 2012;15:97-102.

19. Hristov M, Weber C. Endothelial progenitor cells in vascular repair and remodelling. Pharmacol Res. 2008;58:148-151.

20. Simons D, Grieb G, Hristov M et al. Hypoxia-induced endothelial secretion of macrophage migration inhibitory factor and role in endothelial progenitor cell recruitment.J Cell Mol Med. 2011;15:668-678.

21. Hristov M, Zernecke A, Liehn EA et al. Regulation of endothelial progenitor cell homing after arterial injury. Thromb Haemost. 2007;98:274-277.

22. Hristov M, Weber C. Endothelial progenitor cells: characterization, pathophysiology, and possible clinical relevance. J Cell Mol Med. 2004;8:498-508.

23. Hristov M, Erl W, Weber PC. Endothelial progenitor cells: isolation and characterization. Trends Cardiovasc Med. 2003;13:201-206.

24. Rakusan K, Flanagan MF, Geva T et al. Morphometry of human coronary capillaries during normal growth and the effect of age in left ventricular pressure-overload hypertrophy. Circulation. 1992;86:38-46.

25. Kushner EJ, Weil BR, MacEneaney OJ et al. Human aging and CD31+ T-cell number, migration, apoptotic susceptibility, and telomere length.J Appl Physiol. 2010;109:1756-1761.

26. Kushner EJ, MacEneaney OJ, Weil BR et al. Aging is associated with a proapoptotic endothelial progenitor cell phenotype. J Vasc Res. 2011;48:408-414.

27. Khan A, Karpawich PP. New directions in device therapies among children and adults with congenital heart. Expert Rev Cardiovasc Ther. 2010;8:1683-1688.

Submitted: 25 February, 2013

Accepted after reviews: 26 November, 2013 